\title{
EDUCAÇÃO DO CAMPO NA FORMAÇÃO DE PROFESSORES DO CURSO DE PEDAGOGIA DA UFMA - CAMPUS IMPERATRIZ
}

\author{
EDUCACIÓN DE CAMPO EN LA FORMACIÓN DE PROFESORES DEL CURSO DE \\ PEDAGOGÍA EN UFMA - CAMPUS IMPERATRIZ
}
FIELD EDUCATION IN THE TRAINING OF THE PEDAGOGY COURSE PROFESSORS FROM UFMA - CAMPUS IMPERATRIZ

\author{
lara Rodrigues da Silva ${ }^{1}$ \\ ORCID 0000-0002-5706-3614 \\ Isabela Mendes Costa Campos ${ }^{2}$ \\ ORCID 0000-0002-0186-6194 \\ Witembergue Gomes Zaparoli3 \\ ORCID 0000-0003-3452-2600 \\ Ubiratan Francisco de Oliveira ${ }^{4}$ \\ ORCID 0000-0002-0507-9251
}

\section{Resumo}

O estudo aborda a temática de Educação do Campo com foco na formação de educadores. Tem por objetivo fazer uma breve análise do currículo do curso de Pedagogia do Centro de Ciências Sociais, Saúde e Tecnologia - (CCSST) da Universidade Federal do Maranhão - UFMA/Campus de

\footnotetext{
${ }^{1}$ Mestranda em Formação Docente em Práticas Educativas -PPGFOPRED (UFMA). Membro do Grupo de estudo e pesquisa Diálogos Interculturais e Práticas Educativas (DIPE). Monitora de Educação na Família Agrícola do Bico do Papagaio Padre Josimo. E-mail: iararodriguesuft@gmail.com

${ }^{2}$ Mestranda em Formação Docente em Práticas Educativas -PPGFOPRED (UFMA). Membro do Grupo de Estudo e Pesquisa Diálogos Interculturais e Práticas Educativas (DIPE). Assistente Social da UFMA. E-mail: isabelamendesas@gmail.com

3 Doutor em Letras (UFT/ Araguaína). Coordenador do Grupo de Estudo e Pesquisa Diálogos Interculturais e Práticas Educativas (DIPE). Docente do Programa de Pós-graduação em Educação com área de concentração em Formação Docente em Práticas Educativas - PPGFOPRED (UFMA). E-mail: wg.zaparoli@ufma.br

4 Doutor em Geografia (UFG). Membro do Grupo de Pesquisa Espaço, Sujeito e Existência - Dona Alzira-IESAUFG. Integrante do grupo de pesquisa Agroecologia e Nova Cartografia Social (GEPACS/UFT). Docente do Magistério Superior na Universidade Federal do Norte do Tocantins (UFNT) - Curso de Educação do Campo Campus Tocantinópolis. E-mail: bira@mail.uft.edu.br
}

\section{Como referenciar este artigo:}

SILVA, I. R.; CAMPOS, I. M. C.; ZAPAROLI, W. G.; OLIVEIRA, U. F. Educação do Campo na formação de professores do curso de Pedagogia da UFMA - Campus Imperatriz. Revista Pedagógica, v. 23, p. 1-17, 2021. 
Imperatriz, buscando identificar a existência do debate sobre Educação do Campo na formação dos educadores. Utilizou-se como metodologia a revisão bibliográfica, com destaque para os estudos de Arroyo (2004; 2012), Caldart (2002; 2004), Candau (2007) e Molina (2004; 2015), além de análise documental do Projeto Pedagógico do Curso de pedagogia e do plano de ensino da disciplina de Educação do Campo. Os resultados permitem identificar que o debate no curso de pedagogia sobre a temática em questão é realizado no âmbito de uma disciplina optativa e, portanto, com pouca frequência. Todavia, outras disciplinas também apresentam em suas ementas conteúdos afins, possibilitando o contato com a discussão, embora de forma limitada, bem como o entendimento da sua importância no contexto plural em que os educadores são inseridos.

Palavras-Chave: Currículo. Educação do Campo. Políticas Públicas.

\title{
Resumen
}

El estudio aborda el tema de la Educación Rural con un enfoque en la formación de educadores. Tiene como objetivo hacer un breve análisis del plan de estudios del curso de Pedagogía del Centro de Ciencias Sociales, Salud y Tecnología - CCSST de la Universidad Federal de Maranhão - UFMA / Campus de Imperatriz, buscando identificar la existencia del debate sobre Educación Rural. en la educación de educadores. Se utilizó una metodología de revisión bibliográfica, con énfasis en los estudios de Arroyo (2004; 2012), Caldart (2002; 2004), Candau (2007) y Molina (2004; 2015), además del análisis documental del Proyecto Pedagógico del Curso de Pedagogía y del plan de enseñando para el campo de la Educación Rural. Los resultados permiten identificar que el debate en el curso de pedagogía sobre el tema en cuestión se lleva a cabo en el ámbito de una asignatura optativa y, por tanto, con poca frecuencia. Sin embargo, otras disciplinas también presentan contenidos similares en sus menús, lo que permite el contacto con la discusión, aunque de forma limitada, así como la comprensión de su importancia en el contexto plural en el que se insertan los educadores.

Palabras clave: Currículum. Educación rural. Políticas públicas.

\begin{abstract}
The study addresses the Field Education theme focusing on training of educators. It aims to make a brief analysis of the curriculum of the Pedagogy course of the Center for Social Sciences, Health and Technology - CCSST of the Federal University of Maranhão - UFMA / Campus of Imperatriz, seeking to identify the existence of the discussion about Field Education in the training of educators. A bibliographic review methodology was used, with emphasis on the studies by Arroyo (2004; 2012), Caldart (2002; 2004), Candau (2007) and Molina (2004; 2015), in addition to documentary analysis the Pedagogical Project of the Pedagogy Course and the teaching plan for the field of Rural Education. The results allow us to identify that the discussion in the pedagogy course about the subject in question is carried out within the scope of an elective course, and, therefore, with little frequency. However, other disciplines also present similar contents in their menus, enabling contact with the discussion, although in a limited way, as well as the understanding of its importance in the plural context in which educators are inserted.
\end{abstract}

Keywords: Curriculum. Field Education. Public policy.

\section{INTRODUÇÃO}


A constituição das práticas educativas voltadas para o povo do campo emerge em meio à necessidade de diferentes grupos sociais acessarem a educação. Como fruto de uma demanda pleiteada pelas organizações e movimentos sociais do campo, a Educação do Campo delineia-se inserida nas lutas sociais, na perspectiva de desenvolver uma prática compromissada com os interesses dos campesinos e sua emancipação humana.

A crescente demanda por pesquisas sobre Educação do Campo no contexto da realidade socioeducacional das escolas do meio rural no Brasil nos remete à necessidade de pesquisas para a compreensão da realidade atual dos processos educativos dos camponeses; trabalhadores rurais; ribeirinhos; quilombolas e indígenas, e aponta para um histórico de lutas sociais dos povos do campo, com ênfase para a formação dos educadores que atuarão no campo.

Neste contexto de lutas pela afirmação de uma política pública para o povo do campo, aponta-se a formação dos educadores como um aspecto central para a implementação da Educação do Campo, uma vez que os docentes têm um papel fundamental na construção de práticas educativas capazes de desencadear mudanças significativas na realidade dos sujeitos. Nesse sentido, é necessário investir em formação que contribua com a maior compreensão dos camponeses, considerando a totalidade dos processos sociais e culturais em que estão imersos.

O presente artigo apresenta uma discussão a respeito da Educação do Campo na formação de professores e tem por objetivo fazer uma breve análise do currículo do curso de Pedagogia do Centro de Ciências Sociais, Saúde e Tecnologia - CCSST da Universidade Federal do Maranhão - UFMA/Campus de Imperatriz, buscando identificar a existência do debate sobre Educação do Campo na formação dos educadores.

Quanto ao percurso metodológico, a pesquisa possui abordagem qualitativa e navegou no uso da pesquisa documental, uma vez que a necessidade explorativa se inicia com o entendimento da trajetória da Educação do Campo e os processos de escolarização no Brasil, avançando na compreensão da formação dos educadores que atuarão diretamente nos espaços escolares situados na zona rural e/ou no campo. A análise dos documentos apreciados, o PPC do curso de Pedagogia, a estruturação do currículo e o plano de ensino da disciplina de Educação do Campo desafia-nos a compreender a construção docente de educadores habilitados ao campo como uma necessidade real, 
visto que a sociedade brasileira caminha a passos lentos no que se refere ao trato específico e diferenciado com os povos do campo, que venha garantir um debate aprofundado sobre a temática. Esta análise foi dialogada com uma base teórica com destaque para os estudos de Arroyo (2004; 2012), Caldart (2002; 2004), Candau (2007) e Molina (2004; 2015) e compreendida a partir da categoria formação docente no ensino superior.

Dividido em duas seções, o artigo busca, inicialmente, abordar particularidades da Educação do Campo a partir de apontamentos sobre a luta para sua materialização enquanto política pública. Nessa direção, ressalta-se a importância de incorporar aos currículos dos cursos de graduação especificidades da temática da Educação do Campo no intuito de possibilitar a atuação junto aos camponeses. Apresenta-se então, o que já se tem de conquistas neste sentido, a exemplo da implementação das Licenciaturas em Educação do Campo (LEDOCS), modalidade de graduação voltada para formação de educadores para atuarem nas escolas do campo, além de chamar atenção para a necessidade de uma maior abrangência da discussão no contexto das Instituições de Educação Superior.

Na segunda seção são abordadas questões concernentes ao curso de Pedagogia da UFMA, campus Imperatriz, na perspectiva de identificar como a temática da Educação do Campo vem sendo trabalhada junto aos acadêmicos. Na oportunidade, realizou-se uma análise do PPC do curso de pedagogia, bem como do plano de ensino da disciplina de Educação do Campo, a qual é ofertada como disciplina optativa. Nessa direção, espera-se apontar caminhos para uma reflexão sobre a formação de educadores alinhada às realidades diversas, em especial, à realidade do campo. Esta reflexão incidirá na perspectiva de problematizar a proposta de currículo, aqui, objeto de nosso estudo.

Declara-se que para realização deste estudo levou-se em consideração a necessidade da reflexividade ética, de modo a não prejudicar outros indivíduos, grupos e instituições ou mesmo potencializar ou legitimar discursos que intensificam ideias com as quais não concordamos, a exemplo da supremacia entre povos. Ao buscar identificar a existência do debate sobre Educação do Campo na formação de educadores, foi solicitada junto à coordenação do curso de pedagogia da UFMA, campus Imperatriz, a disponibilização do atual PPC, bem como do plano de ensino da disciplina de Educação do 
Campo, requerendo o consentimento para o acesso e utilização destes documentos e garantindo o cuidado com o rigor na realização da análise.

\section{AS CONTRIBUIÇÕES DA EDUCAÇÃO DO CAMPO NO ÂMBITO DA FORMAÇÃO DE EDUCADORES}

A Educação do Campo no Brasil é uma política recente, considerando o contexto histórico da educação no país. Nasceu primeiro como Educação Básica do Campo a partir da organização coletiva dos movimentos sociais no contexto de preparação da I Conferência Nacional de Educação do Campo em 1998 na cidade de Luziânia, em Goiás, passando a se chamar Educação do Campo a partir das discussões do seminário Nacional realizado em Brasília (CALDART, 2012). Desde então, a luta no país por acesso à escola de qualidade no meio rural vem adquirindo visibilidade e força.

Ao discutir sobre a Educação do Campo é necessário compreender que se trata de uma educação construída a partir dos saberes populares, num processo dialógico entre o conhecimento local adquirido nas vivências cotidianas e outras formas de conhecimento. Em sua dinâmica, destina-se a grupos de moradores e trabalhadores do campo e intervém de forma significativa na vida destes, uma vez que com base nos conhecimentos previamente já vivenciados abre caminho para novas possibilidades. Nessa direção, Arroyo, Caldart e Molina (2004, p. 12) apontam que:

Aqui se entende por Educação do Campo um movimento de ação, intervenção, reflexão, qualificação que tenta dar organicidade e captar, registrar, explicitar e teorizar sobre múltiplos significados históricos, políticos e culturais consequentemente formadores, educativos.

A partir da dinâmica dos povos do campo e por intermédio de movimentos e organizações sociais que lutam pelos seus direitos, surge a Educação do Campo, com características diferenciadas em razão das especificidades do espaço cultural e social em que está inserida. Neste contexto de lutas por um ensino significativo, busca-se superar a rotulação dos sujeitos do campo como inferiores e, portanto, não merecedores de uma educação de qualidade. 
Nesse entendimento Santos (2017) afirma que em seu contexto histórico, a Educação do Campo vivenciou processos de estigmatização, sendo considerada inferior quando comparada à educação dos espaços urbanos. O campo é reconhecido pelos movimentos sociais como um espaço de lutas e embates políticos, favorável a reflexões sociais e que detém tradições, místicas e costumes próprios. Segundo o autor, trata-se de um contexto singular que demanda uma educação diferenciada e não apenas uma extensão da escola urbana. Desse modo, a utilização do termo rural foi substituída pelo termo campo, alteração que se deu a partir dos movimentos sociais e que abrange uma compreensão do conceito, no sentido de superar e romper com o conservadorismo presente na educação rural.

Desenvolvida como fruto de demandas das organizações e movimentos sociais, a Educação do Campo faz emergir uma nova concepção sobre o campo, superando a visão de atraso e de plano inferior no sentido de valorizar os conhecimentos específicos da prática dos campesinos. Assim, enfatiza-se o campo como lugar de trabalho, moradia, mas também de construção de saberes e identidades. Tal concepção expressa a busca pela educação aliada à valorização da identidade e da cultura da população camponesa.

A luta do povo do campo por políticas públicas que garantam o seu direito à educação é um dos traços principais dos movimentos e organizações sociais do campo, uma vez que partem da perspectiva da educação enquanto um direito universal e que deve ser desenvolvida como tal. Conforme apontado por Caldart (2002) a Educação do Campo tem se concretizado em muitos lugares por meio de experiências como programas, práticas comunitárias, dentre outras vivências pontuais. Todavia, a autora enfatiza que é preciso ter clareza de que isto não basta e que a luta é no campo das políticas públicas, sendo a única maneira de universalizar o acesso de todo o povo à educação.

No que se refere à concepção de uma educação que respeite às singularidades culturais e regionais da sociedade brasileira, são identificados avanços sobretudo nos instrumentos legais, a exemplo da Constituição Federal de 1988 e da Lei de Diretrizes e Bases da Educação Nacional (LDBEN), Lei 9.394/96 (BRASIL, 1996). Todavia, embora a Educação do Campo seja concebida como política pública, ainda é precária a realidade das escolas para população campesina. 
Nessa direção, Santos (2017) afirma que a Educação do Campo tem sido historicamente marginalizada na construção de políticas públicas, sendo diversas vezes tratada como política compensatória. O autor salienta um cenário de descaso ao mencionar alguns problemas que precisam ser solucionados, tais como a limitação dos recursos destinados às escolas, o deslocamento marcado pela precariedade dos transportes e estradas, escolas distantes das residências dos estudantes, formação dos educadores/as e organização curricular, oferta limitada de vagas para os estudantes do campo nas séries finais do ensino fundamental e médio, dentre outros problemas que potencializam a concepção de uma educação rural, ainda marcada pelo conservadorismo.

Dentre os diversos desafios que a Educação do Campo enfrenta para se materializar, destaca-se aqui a formação dos educadores, os quais são componentes essenciais neste contexto, mas que em seu processo formativo nem sempre têm oportunidade de ter contato com a temática de Educação do Campo. De acordo com Gehrke (2014, p. 80),

No cenário da educação rural, um dos grandes limitadores, diagnosticado pelos movimentos sociais, foi a necessidade de formação de professores para atuar nas escolas do campo, tanto naquelas já existentes, quanto naquelas a serem reabertas e criadas no contexto camponês brasileiro.

Reconhecer a real necessidade de investir na formação de educadores que atenda às demandas dos povos do campo pode tornar a universidade um espaço mais aberto a processos de formação que vá ao encontro dos objetivos da educação voltada para o referido público.

No âmbito do ensino superior, Molina (2015) destaca que no contexto das políticas de expansão da educação superior no Brasil (2013 a 2017), uma das frentes de expansão tem se dado na formação de educadores do campo, sendo implementados 42 cursos em Instituições de Educação Superior (IES) brasileiras na modalidade de graduação intitulada Licenciatura em Educação do Campo (LEDOC), com participação dos movimentos sociais em sua concepção e elaboração, considerando que a criação de uma política pública de apoio à formação de educadores sempre constou como prioridade na luta pela efetivação da Educação do Campo.

Sobre essa questão, Molina (2015, p. 147) enfatiza que: 
Essa ampliação, por sua vez, faz parte de uma das mais recentes políticas de Estado, lançada em 2012, e intitulada Programa Nacional de Educação do CampoPronacampo, que objetiva oferecer apoio técnico e financeiro aos estados, Distrito Federal e municípios para implementação da Política Nacional de Educação do Campo, devendo atender Escolas do Campo e Quilombolas, a partir de quatro eixos de ação: 1. Gestão e Práticas Pedagógicas; 2. Formação de Educadores; 3. Educação Profissional e Tecnológica; e 4. Infraestrutura. É dentro do Eixo 2 que se localiza especificamente a ação do Estado responsável por apoiar e fazer acontecer a implantação dos 42 novos cursos de Licenciatura em Educação do Campo - LEDOC, através de um Subprograma intitulado Programa de Apoio às Licenciaturas em Educação do Campo - Procampo.

Neste sentido, o desafio das LEDOCs é o de materializar práticas formativas que desenvolvam e promovam nos futuros educadores as habilidades necessárias para contribuir com a consolidação de uma Escola do Campo, ideal edificado pelo movimento protagonizado pelos camponeses nos últimos 15 anos (Molina, 2015). Todavia, embora as LEDOCs sejam uma conquista significativa neste movimento de afirmação da política pública de Educação do Campo nas universidades, o debate sobre a temática de um modo geral ainda é limitado, considerando que são raros os conteúdos e disciplinas trabalhados nos cursos de graduação, o que impossibilita os estudantes de licenciaturas, em sua maioria, de terem conhecimento e entenderem a necessidade da discussão para sua formação enquanto futuro educador.

É importante salientar que no processo formativo dos educadores é essencial a preparação para o desenvolvimento de práticas contra-hegemônicas, tendo em vista que na Educação do Campo é necessário possibilitar aos alunos perceberem e valorizarem os seus processos socioculturais para então transformarem sua própria realidade. Nessa mesma perspectiva Freire (2013, p. 31), ao falar sobre os saberes necessários às práticas educativas dos educadores, enfatiza que "ensinar exige respeito aos saberes dos educandos" e nesse processo coloca ao professor ou mais amplamente à escola, o dever de respeitar os saberes socialmente construídos na prática comunitária.

Nesse entendimento, é fundamental que os docentes tenham a oportunidade de, ainda na sua formação acadêmica, acessarem uma estrutura curricular e práticas formativas que possibilitem o contato com as realidades diversas, com foco para uma educação que, de fato, atenda as reais necessidades da população a qual se destina. Diante desse cenário, Poso e Monteiro (2021) abordam a importância da perspectiva decolonial 
nos cursos de formação de professores e destacam a importância de uma formação de professores que respeite a cultura e a identidade dos diversos sujeitos e sujeitas:

\begin{abstract}
Uma formação de professores que possa pleitear a valorização das multiculturas, problematizando axiomas, sacudindo as certezas, respeitando as diferenças, superando a racionalidade técnica e que esteja engajada com a construção identitária deste futuro docente, almejando uma educação democrática, inclusiva e comprometida com a emancipação social é um caminho frutífero para alcançar as apetecidas transformações (POSO; MONTEIRO, 2021, p. 4).
\end{abstract}

Demanda-se, então, dos currículos dos cursos de graduação que sejam incorporados saberes que vão ao encontro da garantia do direito à educação dos povos do campo. No entendimento de Arroyo (2012, p. 361) é essencial na formação de educadores do campo "reconhecer os saberes do trabalho, da terra, das experiências e das ações coletivas sociais e legitimar esses saberes como componentes teóricos dos currículos". Portanto, infere-se que tanto os licenciandos quanto os grupos e movimentos sociais sejam protagonistas neste processo de formação. Além disso, a universidade é um espaço de construção e tem o papel de fomentar e oportunizar aos estudantes uma formação que contemple a totalidade dos indivíduos em sua complexidade e pluralidade.

\title{
1.1 A Educação do Campo e o currículo do curso de pedagogia da UFMA- Imperatriz
}

A formação de educadores e educadoras do campo e para o campo é considerada primordial e de extrema necessidade no contexto de afirmação e implementação da política pública em questão. Com base em Candau e Moreira (2007, p. 19) “O papel do educador no processo curricular é, assim, fundamental. Ele é um dos grandes artífices, queira ou não, da construção dos currículos que se materializam nas escolas e nas salas de aula." A partir deste entendimento, reforça-se o interesse em compreender como estão sendo desenvolvidas as abordagens relacionadas à temática de educação do campo na formação dos educadores, em particular na graduação.

Com o objetivo de identificar a existência do debate sobre Educação do Campo no âmbito da formação dos estudantes do curso de Pedagogia da UFMA, campus Imperatriz, recorreu-se ao PPC e ao plano de ensino da disciplina de Educação do Campo. 
A educação é direito de todos e dever do Estado e da família, conforme disposto na Constituição Federal Brasileira de 1988 em seu Art. 205 (BRASIL, 1988). Desse modo, é direito dos povos do campo a igualdade de condições para o acesso e permanência na escola. É a partir desta premissa que se consolida a luta dos povos do campo por uma educação de qualidade, que contemple suas especificidades e compreenda os saberes produzidos, articulados e sistematizados dos sujeitos e sujeitas do campo.

É importante salientar que a Educação do Campo é um modelo de educação que se diferencia da educação urbanocêntrica 5 ofertada no campo, a qual não é pensada com base na realidade dos sujeitos, sendo importado o currículo do espaço urbano. Ao discutir educação do campo, as lutas sociais devem ser consideradas e o currículo repensado a partir da afirmação da identidade e fortalecimento da permanência dos jovens no campo. Dessa forma, faz-se necessária a efetivação de um currículo próprio que atenda as demandas dos povos campesinos.

No que se refere ao currículo, deve-se considerar a estreita relação com as relações de poder, as quais são envolvidas nos processos de seleção de determinado conhecimento em detrimento de outros, conforme apontado por Michel Apple citado por Silva (2005). Nessa direção, a construção de um currículo aponta um processo que reflete em interesses específicos. Parte-se então, da perspectiva de que o currículo é complexo porque precisa entender e contemplar as especificidades dos sujeitos. Sacristán (2013) afirma que o currículo não é somente um documento e sim construção social e práxis educativa. Portanto, o processo da sua construção deve atender as relações sociais e culturais dos sujeitos e sujeitas e adaptar-se a realidades diversas, como a dos indígenas, quilombolas, ribeirinhos, extrativistas e camponeses em um processo dialógico e de fortalecimento da sua identidade.

Para se efetivar a educação do campo que contemple a realidade dos sujeitos educandos do meio rural é necessária a compreensão dos princípios fundamentais da educação do campo e para o campo. Arroyo (2014, p. 33) aponta que

\footnotetext{
5 "O urbanocentrismo constitui-se na lógica adotada pelo sistema, como estratégia de regulação e controle da educação nacional, expressando o ideal homogeneizador, o que marginaliza e silencia as experiências produzidas no âmbito rural” (PINHO; SANTOS, 2007, p. 12)
} 
[...] ao lutarem pelo direito à educação, ao conhecimento, à herança cultural compactuam a mesma lógica: 'OCUPEMOS O LATIFÚNDIO DO SABER” passou a ser o grito político dos militantes/educadores que chegam aos cursos de Pedagogia da Terra, de formação de Educadores indígenas, quilombolas, do campo.

Na oportunidade da análise do PPC de pedagogia da UFMA, campus Imperatriz, identificou-se que a proposta se fundamenta nas Diretrizes Curriculares Nacionais (DCNs) para o curso de Pedagogia, consubstanciadas nos Pareceres CNE/CP nº. 05/2005 e na Resolução CNE/CP n. 01/2006, bem como na Resolução n 1.175/2014 CONSEPE/UFMA, que aprova as normas regulamentadoras dos cursos de graduação da UFMA. Além disso, contempla a Resolução $n^{\circ} 2$, de $1^{\circ}$ de julho de 2015 que define as Diretrizes Curriculares Nacionais para a formação inicial em nível superior (cursos de licenciatura, cursos de formação pedagógica para graduados e cursos de segunda licenciatura) e para a formação continuada. Cabe destacar que o PPC sofreu alterações curriculares ao longo dos anos.

A análise foi realizada com foco na ementa da disciplina de Educação do Campo, na perspectiva de entendimento da discussão no contexto da Universidade Federal do Maranhão, campus Imperatriz. Com base na leitura do PPC, foi possível identificar que o curso em análise tem por objetivo formar educadores e educadoras para trabalharem na educação infantil, nos anos inicias do ensino fundamental e na educação de jovens e adultos, além de preparar para as funções de suporte pedagógico, como direção, supervisão e orientação educacional. A base ética e política pretendida para e pelo Curso de Pedagogia do CCSST está centrada na categoria de humanização.

Conforme descrito no PPC em questão, seu processo de reorganização em 2017 teve como base diversos aspectos. Primeiramente, foi o entendimento de que o projeto do curso, em vigor desde 2001, não contemplava mais as necessidades emergentes da comunidade local. O corpo docente foi progressivamente renovado com a efetivação de novos professores. E ainda, o fato de o Campus II tornar-se Centro, o que, consequentemente, exige uma proposta pedagógica que atenda às especificidades de cada curso e seu respectivo público. Por conseguinte, as transformações ocorridas no cenário educacional nacional sustentam essa necessidade constante de ampliação, aprimoramento e redimensionamento do saber-fazer educacional. 
No percurso de análise do PPC do curso, identificou-se a existência da disciplina de Educação do Campo, todavia, ofertada enquanto disciplina eletiva, não sendo frequente a sua realização. Algumas abordagens se fazem necessárias para a compreensão da importância dessa disciplina de forma obrigatória, considerando que em pleno movimento de afirmação da política pública de educação do campo nas universidades brasileiras, o curso de pedagogia da UFMA inviabiliza a obrigatoriedade da disciplina, o que dificulta à compreensão dos acadêmicos no que diz respeito às particularidades de uma política tão necessária e que surge para atender aos interesses do povo do campo, tão presente na realidade do estado do Maranhão.

Como afirmam Candau e Moreira (2007, p. 31) “elaborar currículos que atendam e respeite a cultura, demanda uma nova postura, por parte da comunidade escolar, de abertura às distintas manifestações culturais". Desse modo, é importante considerar a diversidade dos processos sociais e culturais que os sujeitos e sujeitas do campo estão inseridos, para que sejam incorporados na formação dos educadores elementos que viabilizem sua compreensão sobre a dinâmica campo, bem como sobre a necessidade de sua habilitação para atuar junto às comunidades do campo, valorizando saberes populares e as vivências cotidianas.

Ao considerar que os profissionais graduados no curso de pedagogia da UFMA atendem às escolas dos municípios da região, muitas destas inseridas em um contexto rural em torno da cidade, entende-se que o debate da educação do campo, enquanto disciplina, deveria ser obrigatório. Além disso, destaca-se que as escolas inseridas no espaço urbano também atendem a estudantes do campo, o que reforça a necessidade de ainda na formação acadêmica, os educadores terem acesso à discussão de forma aprofundada.

A disciplina de Educação do Campo ofertada no curso de pedagogia do CCSST/UFMA conta com uma carga horária de 6oh na modalidade de Estudos Diversificados I. A disciplina não é realizada há dois anos, tendo em vista seu caráter eletivo e a ausência de demanda por parte dos estudantes. Entende-se assim, que o fato de não ser ofertada regularmente no rol de disciplinas obrigatórias impede o contato e o entendimento da necessidade dessa discussão durante a formação acadêmica.

A partir da leitura da ementa da disciplina, identificou-se que há o entendimento da necessidade de processos educativos voltados ao conjunto dos trabalhadores e 
trabalhadoras do campo, incluindo as populações indígenas e remanescentes de quilombos, vinculados à luta e ao trabalho no meio rural em defesa da reforma agrária e da educação pública. Dessa forma, busca-se por meio da disciplina abordar as três categorias principais dentro desse processo educativo: o movimento por uma Educação do Campo; a Pedagogia da Alternância e a Educação do Campo em Imperatriz.

Percebe-se que embora a disciplina seja ofertada de forma eletiva, os docentes que estão à frente da temática no curso mantém um esforço no sentido de garantir que as discussões sejam pautadas na universidade. Por meio do plano de ensino (2018), identificou-se que o objetivo da disciplina é o de

\footnotetext{
Desenvolver (re)leitura da História da Educação no Brasil sobre a ótica da Educação do Campo e os pressupostos dos Movimentos Sociais para tais fatos e rupturas, promovendo a formação de educadores para atuar nas diferentes etapas e modalidade da educação básica dirigida às populações que trabalham e vivem no campo.
}

Desse modo, são trabalhados conteúdos que possibilitam ao discente compreender o lugar da Educação do Campo nas políticas públicas no Brasil, bem como refletir sobre os aspectos que caracterizam diferentes realidades, criando debate sobre a interdisciplinaridade no processo de formação. Dentre os conteúdos da disciplina tem-se: Categorias de Educação no Campo; Movimentos Sociais e do Campo; Povos no/do campo; Escola e Pedagogias no Campo; e Políticas Educacionais no Campo, os quais são trabalhados por meio de aulas expositivo-dialogadas, trabalho de grupo, seminários de leituras e para apresentação de dados de pesquisa e relatos de experiências, investigação científica, viagens e visitas de estudos.

A proposta da disciplina atende a real necessidade de contribuir para o desenvolvimento de um projeto educativo que seja articulado com as estratégias de emancipação humana dos sujeitos do campo, tendo a educação como eixo central para alcançar este objetivo. Partindo da reflexão sobre a temática da educação do campo e os seus desdobramentos no contexto da universidade, entende-se que o processo formativo do profissional deve englobar elementos que contemplem a pluralidade dos sujeitos, uma vez que atuar nesta realidade demanda entendimento da sua essência, no sentido de 
compreender que a lógica do processo de ensino dos povos do campo é permeada por lutas históricas coletivas. Oliveira (2016) enfatiza que:

O professor e a professora do campo, independente da área de conhecimento que irão trabalhar, necessitam conhecer o processo histórico do surgimento da educação do campo e saber que não existe reforma agrária sem educação do campo, como não existe educação do campo sem reforma agrária. Uma se alimenta da outra. A educação do campo existe para contribuir com a construção do campo para o camponês e seus povos tradicionais (OLIVEIRA, 2016, p. 117).

Em se tratando do curso de pedagogia da UFMA, campus Imperatriz, enfatiza-se a importância de trazer em seu currículo a disciplina de Educação do Campo, bem como bibliografias relacionadas à temática em outras disciplinas, a exemplo de "Estado, movimentos sociais e políticas públicas". Porém, entende-se que caso a disciplina específica de Educação do Campo estivesse no rol das obrigatórias, a temática certamente seria abordada de forma mais enfática junto aos acadêmicos, possibilitando maior compreensão deste contexto, o qual possui suas particularidades e que precisa ser discutido no âmbito da universidade.

Demanda-se, então, interesse e esforço para pensar a educação do campo em sua totalidade, contemplando as categorias território, lutas sociais e questões agrárias. Para tanto, adotar um espaço na "grade" curricular de forma regular é essencial para o entendimento sobre o campo, o contexto de pertencimento dos sujeitos, suas práticas e necessidades. Assim, seria possível atrelar os diferentes saberes por meio de práticas interdisciplinares desenvolvidas no curso.

\section{CONSIDERAÇÕES FINAIS}

A discussão sobre a educação do campo no âmbito da formação de educadores é fundamental para a construção de processos formativos que coadunem com a diversidade existente na realidade do Brasil. Chama-se atenção aqui, para a necessidade de formar educadores e educadoras de modo a transcender modelos de ensino fragmentados, que não consideram os processos culturais, políticos e sociais em que os estudantes estão inseridos. 
Conhecer o contexto em que emerge a Educação do Campo, suas especificidades na legislação brasileira, as conquistas alcançadas por meio de lutas sociais e culturais do Movimento da Educação do Campo é de fundamental importância para a formação dos educadores, no sentido de promover uma educação crítica e emancipatória. Nesse sentido, entende-se que o contato com a disciplina de Educação do Campo no curso de pedagogia da UFMA, campus Imperatriz, possibilita ao acadêmico não apenas o debate teórico sobre as lutas do povo, mas o contato direto com as realidades, tendo em vista que são realizadas visitas aos espaços em que se materializam a educação do campo.

Todavia, é importante considerar que o curso de pedagogia da UFMA, campus Imperatriz, embora apresente em seu currículo elementos que contribuem para a discussão sobre a Educação do Campo, ainda o faz de forma limitada, uma vez que a disciplina, a qual traz conteúdos que aprofundam a temática, não é ofertada regularmente. Assim, pelo fato de muitas turmas não optarem pela disciplina dentre as eletivas que devem cursar, a mesma é realizada com baixa frequência. Aspecto que merece destaque, pois a falta de interesse dos universitários pela escolha da disciplina aponta para a possível falta de compreensão sobre sua real importância, permanecendo o não acesso de muitos educadores à temática de forma aprofundada na graduação.

Infere-se então, a relevância da oferta da disciplina de Educação do Campo de forma obrigatória, levando em consideração os avanços dos movimentos de afirmação das políticas públicas da educação do campo nas universidades brasileiras e a emergência de se possibilitar o contato com a temática ainda na formação acadêmica.

Outro aspecto relevante identificado durante a análise é que o curso de pedagogia possui uma vertente social de inclusão dos sujeitos e sujeitas socialmente excluídos do acesso a uma educação que contemple suas realidades e compreenda suas reais necessidades. Assim, é temas como deficiências físicas ou cognitivas, diversidade de gênero e etnia, educação de jovens e adultos e direitos humanos são defendidos e trabalhados no âmbito da formação acadêmica, o que evidencia a construção de um caminho que aponta para uma educação contra-hegemônica, aberta a processos cada vez mais plurais.

Sem a pretensão de haver esgotado o assunto, aponta-se como resultado que a discussão sobre a política pública de Educação do Campo é pautada no curso de pedagogia 
da UFMA, campus Imperatriz, embora que ainda de forma limitada em razão da não obrigatoriedade da disciplina de Educação do Campo. Todavia, foi possível observar conteúdos afins na ementa de outras disciplinas, o que não anula o debate, mesmo nos semestres em que não é ofertada a disciplina eletiva de Educação do Campo. Desse modo, entende-se que o currículo do curso abre caminhos para uma formação que considere contextos diversos e suas especificidades.

\section{REFERÊNCIAS}

ARROYO, Miguel Gonzalez. Formação de educadores do campo. In: CALDART, R. et al (org.). Dicionário da educação do campo. Rio de Janeiro, São Paulo: Escola Politécnica de Saúde Joaquim Venâncio, Expressão Popular, 2012. p. 359-365.

ARROYO, Miguel Gonzalez; CALDART, Roseli Salete; MOLINA, Mônica Castagna (Org.). Por uma educação do campo. Petrópolis, RJ: Vozes, 2004. 214 p.

BRASIL. Constituição Federal. Constituição da República Federativa do Brasil, 1988.

FREIRE, Paulo. Pedagogia da autonomia: Saberes necessários à prática educativa. 46. Eed. Rio de Janeiro: Paz e Terra, 2013.

KOLLING, Edgar Jorge; CERIOLI, Paulo Ricardo; CALDART, Roseli Salete. (Orgs.).

Educação do Campo: identidade e políticas públicas. Brasília, DF: Articulação Nacional Por uma Educação Básica do Campo, 2002. Coleção Por uma Educação Básica do Campo, n. 4.

MOLINA, Monica Castagna. Escola do Campo. In: CALDART, Roseli S. et al. (Orgs.).

Dicionário da Educação do Campo. São Paulo: Escola Politécnica de Saúde Joaquim Venâncio; Expressão Popular, 2012.

MOLINA, Monica Castagna. Expansão das Licenciaturas em Educação do Campo: desafios e potencialidades. Educar em Revista, n. 55, p. 145-166, jan./mar. 2015. Editora UFPR.

MOREIRA, Antônio Flávio B; CANDAU, Vera Maria. Indagações sobre currículo: currículo, conhecimento e cultura. Org. BEAUCHAMP, Jeanete; PAGEL, Sandra Denise;

NASCIMENTO, Aricélia Ribeiro do. Brasília: Ministério da Educação, Secretaria de Educação Básica, 2007.

OLIVEIRA, Ubiratan Francisco. Percursos metodológicos para construção coletiva de identidades na Licenciatura em Educação do Campo-UFT Tocantinópolis. In. SILVA [et.al.] (orgs) Educação do Campo e Formação Docente. Palmas: EDUFT, 2016.

PINHO, Ana Sueli Teixeira de; SANTOS, Stella Rodrigues dos. Educação fundamental no campo: por uma educação liberta do modelo escolar "urbanocêntrico". Bahia: Educação Fundamental, n.13, 2007. Disponível em: 
http://3oreuniao.anped.org.br/minicursos/ementa\%20do\%20minicurso\%20do\%2ogt13.pdf Acesso em 12 mai. de 2021.

POSO, Fabiana. F; MONTEIRO, Bruno. A. P. A Perspectiva decolonial nos cursos de formação de professores: uma revisão de literatura. Revista Pedagógica, v. 23, p.1-18,2021.

SACRISTÁN, Gimeno. O que significa o currículo. In. Saberes e incertezas sobre o currículo. Porto Alegre: Penso, 2013.

SANTOS, Ramofly Bicalho. História da Educação do Campo no Brasil: o protagonismo dos movimentos sociais. Teias, Micropolítica, democracia e educação. v. 18, n. 51, 2017 (out./dez.).

SILVA, Tomaz Tadeu da. Documentos de identidade: uma introdução às teorias do currículo. Belo Horizonte: Autêntica, 2005. 156 p.

UNIVERSIDADE FEDERAL DO MARANHÃO. Plano de ensino da disciplina Educação do Campo. Curso de Pedagogia. Imperatriz: UFMA, 2018.

UNIVERSIDADE FEDERAL DO MARANHÃO. Projeto Político Pedagógico do curso de Pedagogia da Universidade Federal do Maranhão. Imperatriz: UFMA, 2017.

Recebido em: 19-04-2021

Aprovado em: 30-04-2021

Publicado em: 26-05-2021 